\title{
Características clínicas y mortalidad en pacientes con cáncer de mama avanzado
}

\author{
Pedro Luis Ramos Guette
}

Correos electrónicos: pramos@oncocareltda,pramos152@yahoo.com

\section{Resumen}

Objetivos: el propósito de este estudio fue evaluar supervivencia libre de enfermedad y global, además de los factores pronósticos asociados a estas, en pacientes mujeres con cáncer de mama avanzado.

Métodos: este estudio involucró el análisis de información de la clínica Oncocare en el período comprendido entre el $1^{\circ}$ de enero de 2003 y el 31 de julio de 2012. Se incluyeron todas las pacientes de 18 o más años con diagnóstico de cáncer de mama avanzado (estadios IIIA, IIIB y IIIC). Se construyeron curvas de supervivencia por el método de Kaplan-Meier, se compararon con el método de rangos logaritmos y se realizó un análisis de regresión de rangos proporcionales por Cox.

Resultados: un total de 314 pacientes fueron identificadas en el estudio. La edad media fue de 54,9 años. Los estadios clínicos se distribuyeron así: IIIA, 120 (38,22\%); IIIB, 126 (40,12\%); y IIIC, 68 (21,66\%). Los receptores de estrógenos y los de progestágeno son positivos en un $56,37 \%$, los receptores de HER2 son positivos en el 14,33\%. Las pacientes recibieron quimioterapia neoadyuvante en un $88,85 \%$; los esquemas más frecuentes fueron AC en el $52,33 \%$ y ACT en el $32,26 \%$. Se les administró quimioterapia adyuvante en un $58,92 \%$ y los esquemas más usuales fueron AC en el 36,96\%, ACTH en el $22 \%$ y ACT en el $23 \%$. Las respuestas a la quimioterapia neoadyuvante fueron: respuesta objetiva en un $78,5 \%$, respuesta completa en un $14,34 \%$ y respuesta parcial en un $64,15 \%$. La mediana del tiempo de seguimiento fue de 41,4 meses; durante el seguimiento se observaron $39(12,42 \%)$ eventos de recaída o muerte y 29 (9,24\%) de muerte. Los tiempos de supervivencia libre de enfermedad se ven disminuidos por el compromiso ganglionar masivo HR 1,98 $(1,24-3,15)$, tamaño tumoral mayor de $5 \mathrm{~cm}$ HR 2,30 $(1,05-$ $5,03)$ y estadio clínico IIIIB HR 1,79 $(1,23-2,62)$. Los tiempos de supervivencia global se reducen por la presencia de 10 o más ganglios positivos HR 1,57 (1,16-2,86), pero no hay asociación de las variables estadio clínico, receptor hormonal, receptor HER2 positivo, respuestas objetivas a quimioterapia y tamaño tumoral con el riesgo de muerte.

Conclusión: el riesgo de recaída o muerte aumenta con el compromiso ganglionar masivo, el tamaño tumoral mayor de $5 \mathrm{~cm}$ y el estadio clínico. El riesgo de muerte se incrementa por la presencia de 10 o más ganglios positivos, pero no se relaciona con los otros factores pronósticos analizados.

Palabras clave: cáncer de mama, mortalidad, pronóstico.

\section{Análisis multivariado de los factores que inciden en la mortalidad en pacientes con cáncer de mama receptor hormonal positivo}

\author{
Pedro Luis Ramos Guette
}

Correos electrónicos: pramos@oncocareltda,pramos152@yahoo.com

Resumen

Objetivo: la meta de este estudio fue evaluar los factores pronósticos relacionados con la supervivencia global y libre de enfermedad con cáncer de mama receptor hormonal positivo.

Métodos: este estudio llevó a cabo el análisis de información de la clínica Oncocare en el período comprendido entre el $1^{\circ}$ de enero de 2003 y el 31 de julio de 2012. Se incluyeron todos los pacientes con diagnóstico de cáncer de mama receptor hormonal positivo (estadios I a IIIC). Se construyeron curvas de supervivencia por el método de Kaplan-Meier, se compararon con el método de rangos logaritmos y se efectuó un análisis de regresión de rangos proporcionales por Cox.

Resultados: un total de 387 pacientes fueron identificados en el estudio. La tasa de mortalidad de la cohorte fue del 7,24\% de pacientes y recaídas del 9,82\%. La edad media fue de 55,3 años; la mediana de seguimiento fue 48,2 meses.

Los estadios clínicos se distribuyeron en estadio I con el 10,85\%, IIA con el $16,28 \%$, IIIB con el $17,05 \%$, IIIA con el $22,74 \%$, IIIB con el $19,12 \%$, IIIC con el $13,95 \%$. Los receptores de HER2 fueron positivos en un 13,7\%.

Palabras clave: cáncer de mama, pronóstico, receptor hormonal.
Los pacientes recibieron quimioterapia neoadyuvante en un $60,72 \%$, del tipo AC en un 59,15\% y ACT en un $22,25 \%$. Se les administró quimioterapia adyuvante en un $73,90 \%$, con AC en el $44,91 \%$, trastuzumab en el $14,7 \%$, taxanos en el $23,25 \%$. Las respuestas a la quimioterapia neoadyuvante fueron: respuesta objetiva en un $76,17 \%$, respuesta completa en un $14,89 \%$, respuesta parcial en un $61,28 \%$. Se presentaron recaídas en un $9,82 \%$ (locales: $2,58 \%$, regionales: $1,29 \%$ y sistémicas: $7,75 \%)$. En el análisis multivariado, se evidencia que el número de ganglios positivos de 10 o más disminuye la sobrevida libre de enfermedad HR 2,30 (1,39-2,80). La respuesta clínica objetiva, el tamaño tumoral, el HER2 positivo, los receptores hormonales positivos, la edad y el estadio clínico no modifican la sobrevida libre de enfermedad y global en el análisis multivariado.

Conclusión: los tiempos de supervivencia libre de enfermedad se reducen con 10 o más ganglios positivos; las otras variables analizadas: tamaño tumoral, estadio clínico, edad, HER2 positivo y respuesta clínica objetivas, no afectan la sobrevida global y libre de enfermedad. 